\title{
Evaluation of the Anti-Hyperlipidemic Activity of Nelumbo nucifera Fruit in Rabbits Fed with High Cholesterol Diet
}

\author{
Muhammad Ali Rajput, Rafeeq Alam Khan*, Tahira Assad \\ Department of Pharmacology, Faculty of Pharmacy \& Pharmaceutical Sciences, University of Karachi, Karachi, Pakistan \\ Email: ^rkhan1959@gmail.com
}

How to cite this paper: Rajput, M.A., Khan, R.A. and Assad, T. (2017) Evaluation of the Anti-Hyperlipidemic Activity of $\mathrm{Ne}$ Iumbo nucifera Fruit in Rabbits Fed with High Cholesterol Diet. Pharmacology \& Pharmacy, 8, 205-213.

https://doi.org/10.4236/pp.2017.86014

Received: May 7, 2017

Accepted: June 20, 2017

Published: June 23, 2017

Copyright $\odot 2017$ by authors and Scientific Research Publishing Inc. This work is licensed under the Creative Commons Attribution International License (CC BY 4.0).

http://creativecommons.org/licenses/by/4.0/

\section{(c) (i) Open Access}

\begin{abstract}
Recently use of herbal therapies and diet rich in flavonoids and vitamins has augmented significantly to manage minor to modest illnesses. Several anti-hyperlipidemic agents are currently available; however most of them have various unwanted effects. That's why more people are switching towards safer alternatives, specially derived from plants with fewer side effects. Hence current study was focused to determine the anti-hyperlipidemic potential of $\mathrm{Ne}$ lumbo nucifera fruit in rabbits fed with high cholesterol diet. This study would surely help in the exploration of a novel agent from the plant source and therefore may recommend the application of traditional medicines in humans. 28 white healthy rabbits of either sex weighing $1000-1500$ gm were divided into four groups. Control group was given gum tragacanth and 3 groups served as test groups and were given $N$. nucifera fruit extract 50, 100 and $200 \mathrm{mg} / \mathrm{kg}$ for 45 days. Initially animals of all four groups received high cholesterol diet (HCD) $0.125 \mathrm{gm} / \mathrm{kg}$ cholesterol in $0.5 \%$ corn oil for 30 days. All drugs were given orally. Blood samples were taken thrice from the ear vein of animals, $1^{\text {st }}$ after 24 hours of thirty days of HCD then again after 24 hours of thirty and forty five days dosing of $N$. nucifera fruit extract. The results showed remarkable cholesterol lowering effects of $N$. nucifera fruit extract at doses 50,100 and $200 \mathrm{mg} / \mathrm{kg}$ but were particularly dominant at $200 \mathrm{mg} / \mathrm{kg}$ at which fruit extract highly significantly reduced TC, TG and LDL-C after 30 and 45 days and increased HDL-C significantly after 30 days and highly significantly after 45 days. Flavonoids, saponins, tannins and procyanidin are significant constituents of $N$. nucifera fruit which may have contributed in lipid lowering effects of $N$. nucifera fruit which can contribute in lowering the risk of CVDs and stroke but more preclinical and clinical studies are required to confirm these findings.
\end{abstract}

\section{Keywords}

Nelumbo nucifera, High Cholesterol Diet, Flavonoids, Procyanidin 


\section{Introduction}

Herbal Medicine or Herbalism is the practice or art of employing herbs and herbal preparations in order to remain healthy and also for the treatment and improvement in prognosis of diseases [1]. The World Health Organization (WHO) has given its estimation that more than $2 / 3 \mathrm{rd}$ of the global population in recent times depends on alternative sources of treatment to fulfill the basic healthcare requirements and this most importantly embroils the usage of plant products. This means that nearby two-thirds of the people globally trust on plants as a reliable way of their medication [2].

These days vigorous research is ongoing to discover nontoxic and beneficial herbs. Several anti-hyperlipidemic agents are currently available; however most of them have associations with various unwanted effects. That's why more people are switching towards safer alternatives, specially derived from plants with fewer side effects [3].

$N$. nucifera belongs to family Nymphaeaceae, and is frequently named as bean of India, Chinese water lily, Indian lotus or merely lotus. According to Linnaean classification $N$. nucifera Gaertn is at present documented name of plant species and is widely cultivated in the tropical regions of Pakistan, India, China, Thailand and Australia [4].

N. nucifera fruit is commonly known as Paban in native language of Sindh province of Pakistan and is cultivated especially in the water gardens, ponds and lakes of interior Sindh (Gotki, Thatta, Larkana and Matiari districts) and in $\mathrm{Mu}-$ zaffergarh regions of southern Punjab, Pakistan. It is also found abundantly in the lakes and streams of Azad Jammu Kashmir (AJK), Pakistan.

Fruit consists of seeds and seed pods. The latter is also known as lotus bulbs, are green in color and provides attachment to the seeds, which are black in color, hard in nature, ovoid, oblongish or roundish in shape, up to $1.5 \mathrm{~cm}$ broad and $1.0 \mathrm{~cm}$ long and are organized in whorls [5]. The seeds are the edible portion and are studded in the pod or bulb and have to be peeled individually before they are eaten. The seed is perhaps the strongest source of protein in the plant [6].

The $N$. nucifera seeds are loaded with fat, amino acid, protein, asparagines, unsaturated fatty acids, minerals, starch, saponins and tannins. The seed has three main components; cotyledons, plumule and integuments, which occupies approximately $93.23 \%, 3.03 \% \& 3.74 \%$ in terms of its mass correspondingly. The average burden of hundred seeds is approximately $87.35 \mathrm{~g}$. The seeds also contain substantial percentage of various minerals such as calcium (22.10\%), potassium $(28.5 \%)$, magnesium (9.2\%), sodium (1.0\%), iron (0.19\%), chromium $(0.004 \%)$, manganese $(0.35 \%)$, zinc $(0.08 \%)$ and copper $(0.046 \%)$. Other significant dietary elements include fat $(72.17 \%)$, proteins $(2.7 \%)$, total powdery residue $(4.5 \%)$, wetness $(10.50 \%)$ and raw fiber $(10.60 \%)$. The seed are highly nutritious and possesses $348.45 \mathrm{cal}$ per $100 \mathrm{~g}$ [7].

The qualitative phytochemical analysis of the seed pods of $N$. nucifera fruit exposed the presence of flavonoids, alkaloids, saponins, tannins and terpenoids 
[1]. Procyanidin was also identified and sequestered from the pods of $N$. nucife$r a$ fruit. The chief secondary metabolites present in N. nucifera seeds are alkaloids, particularly lotusine, liensinine, isoliensinine, dauricine, nuciferine, pronuciferine, roemerine, procyanidin, neferine and armepavine. The seeds also have carbohydrates, Gallic acid and isoquininolinol [4].

Traditionally fruits of $N$. nucifera are used in enormous conditions such as fever, inflammation, insomnia, palpitation, hypertension, arrhythmia, enteritis, chronic diarrhea, spermatorrhea, leucorrhoea, halitosis, skin diseases, leprosy and menorrhagia. It is also used as an antiemetic, antidote, refrigerant and diuretic [8] [9]. Recent study has revealed the LD50 of $N$. nucifera fruit to be greater than $5000 \mathrm{mg} / \mathrm{kg}$ and same study has also demonstrated its anxiolytic and antidepressant activities [1]. However, very limited literature is available regarding its effect on lipid profile, thus current study was focused to determine the anti-hyperlipidemic potential of $N$. nucifera fruit in rabbits fed with high cholesterol diet. This study would surely help in the exploration of a novel agent from the plant source and therefore may recommend the application of complimentary medicines in humans [10].

\section{Materials and Methods}

\section{Experimental design \& methodology}

Research work was executed utilizing the laboratory facilities of Pharmacology department and the Research Institute of Pharmaceutical Sciences, University of Karachi, following approval from the Board of Advance Studies \& Research (BASR), and departmental research \& ethical committee.

\subsection{Selection of Animals}

Anti-hyperlipidemic effect was evaluated in 28 healthy white rabbits of either sex weighing 1000 - $1500 \mathrm{gm}$ which was divided in to four groups; control and 3 test groups. 7 rabbits were placed in each group. Rabbits were chosen as experimental animals for current study as biochemical changes produced in rabbits are very much similar as observed in humans [11]. In addition to it sufficient amount of blood samples can easily be drawn, very convenient to handle and is also economical [12].

\subsection{Animal Housing}

Animals were placed in plastic cages with preservation of room temperature at $23^{\circ} \mathrm{C} \pm 2{ }^{\circ} \mathrm{C}$ and moisture kept at $50 \%$ to $60 \%$ in a substituting 12 -h light/dark succession. Every animal was provided with normal diet prepared in laboratory plus water as desired. The animals were shifted to the laboratory approximately an hour before the commencement of experiments. The experiment was performed during day time. Prior to dose administration, overall fitness of animals were assessed throughout the adaptation phase utilizing the laboratory conditions for a week particularly observing lack of activity, edema, diarrhea and ulceration. 
The research committee Department of Pharmacology permitted the use of animals for these experiments in agreement with the guidelines of $\mathrm{NIH} \mathrm{[13]} \mathrm{and}$ NACLAR [14].

\subsection{Plant Material and Preparation of Extract}

$N$. nucifera fruits were obtained from the local fruit \& vegetable market of Qasimabad, Hyderabad, Sindh, Pakistan. The N. nucifera fruits were identified and authenticated in the Department of Pharmacognosy. The receipt sample no NNF-03 was placed in the section of Pharmacognosy, University of Karachi.

Grounding of crude extract followed cold extraction procedure [15]. $6 \mathrm{~kg}$ fruits were washed and the seeds were peeled off from the seed pods of the fruits manually and were then chopped. After that chopped seeds were dried under shade for 6 days. The dried material was ground to coarse powder. The seed pods on the other hand were dried under shade for 3 days and then chopped to fine powder. The seed powder along with the seed pod powder was macerated in 10 liters of $98 \%$ ethanol for 30 days with occasional shaking and stirring until the color of the solvent becomes black.

The solvent was filtered with the help of Whatman No. 1 filter paper. Afterwards the extract was evaporated under reduced pressure in a rotary evaporator at $40^{\circ} \mathrm{C}$ to $45^{\circ} \mathrm{C}$ followed by freeze drying at $-30^{\circ} \mathrm{C}$. The solid Lyophilized material so obtained was saved at $-20^{\circ} \mathrm{C}$ until further use in doses of 50,100 and $200 \mathrm{mg} / \mathrm{kg}$ orally [1]. The final quantity of the extract obtained was $400 \mathrm{~g}$ of dry mass.

\subsection{Preparation of Drugs}

$0.5 \%$ Corn oil was purchased from local medical stores in Karachi, while gum tragacanth and cholesterol powder were supplied by Merck. High cholesterol diet (HCD) i.e. $0.125 \mathrm{gm} / \mathrm{kg}$ cholesterol in $0.5 \%$ corn oil was given to rabbits for 30 days in order to derange lipid profile [16].

The suspending agent (gum tragacanth powder) was consumed to prepare suspensions of the control and 3 doses of test group ( $N$. nucifera fruit extract 50, $100 \& 200 \mathrm{mg} / \mathrm{kg}$ ). It was administered to control group as placebo in the dose of $10 \mathrm{ml} / \mathrm{kg}$ per oral, every time fresh suspensions were made for the purpose of dosing [17] [18].

\subsection{Effect of N. nucifera Fruit on Lipid Profile}

A population of 28 white healthy rabbits of either sex was divided in to four groups. Control group was given gum tragacanth and 3 groups served as test groups and were given $N$. nucifera fruit extract 50, 100 and $200 \mathrm{mg} / \mathrm{kg}$ for 45 days. Initially animals of all four groups received high cholesterol diet (HCD) i.e. $0.125 \mathrm{gm} / \mathrm{kg}$ cholesterol in $0.5 \%$ corn oil for 30 days. All agents were given PO [16]. Blood samples were taken thrice from the ear vein of animals, 1st after 24 hours of thirty days of HCD then again after 24 hours of thirty and forty five days dosing of $N$. nucifera fruit extract i.e. on 31st and 46th day of experiment.

Blood samples $(5 \mathrm{ml})$ were collected in gel tube. Serum was instantly separated 
by centrifuging blood samples on $14 \mathrm{~K}$ Humax centrifuge at $3000 \mathrm{rpm}$ for 15 min. Lipid profile was investigated on Humalyzer 3000 (semi-automatic chemistry analyzer, Model \#16700) (Human Germany) using standard kits supplied by Human. TC and LDL-C was assessed by CHOD-PAP method; TG by GPO-PAP method [19] and HDL-C according to the method of Friedwald [20].

\subsection{Statistical Analysis}

The data was subjected to analysis by taking average and standard error to the average utilizing two sample student $\mathrm{T}$-test and values of $\mathrm{P}<0.05$ were considered as noteworthy and $\mathrm{P}<0.005$ as extremely noteworthy. All statistical techniques were executed using SPSS software version 20 [21].

\section{Results}

\section{Effects of N. Nucifera Fruit on Lipid Profile}

Table 1 and Table 2 gives the comparative effect of total serum cholesterol (TC), triglycerides (TG), high density lipoproteins (HDL-C) and low density lipoproteins (LDL-C) in animals of control and 3 extract groups after 30 and 45 days.

Table 1. Effect of $N$. nucifera fruit on lipid profile after 30 days.

\begin{tabular}{|c|c|c|c|c|}
\hline \multirow{2}{*}{ Groups } & \multicolumn{4}{|c|}{ Parameters } \\
\hline & Cholesterol mg/dl & Triglycerides mg/dl & $\mathrm{HDL}-\mathrm{C} \mathrm{mg} / \mathrm{dl}$ & LDL-C mg/dl \\
\hline $\begin{array}{c}\text { Control } \\
10 \mathrm{ml} / \mathrm{kg}\end{array}$ & $139.0 \pm 1.30$ & $249.8 \pm 1.80$ & $32.7 \pm 0.68$ & $179.8 \pm 1.10$ \\
\hline $\begin{array}{c}N . \text { nucifera } \\
50 \mathrm{mg} / \mathrm{kg}\end{array}$ & $133.8 \pm 0.40^{\star}$ & $223.1 \pm 0.40^{\star \star}$ & $32.1 \pm 0.74$ & $170.3 \pm 0.68^{\star \star}$ \\
\hline $\begin{array}{l}N . \text { nucifera } \\
100 \mathrm{mg} / \mathrm{kg}\end{array}$ & $118.0 \pm 0.65^{\star *}$ & $180.5 \pm 1.30^{* *}$ & $33.8 \pm 0.34$ & $152.0 \pm 0.82^{\star *}$ \\
\hline $\begin{array}{l}N . \text { nucifera } \\
200 \mathrm{mg} / \mathrm{kg}\end{array}$ & $90.8 \pm 0.86^{\star *}$ & $142.0 \pm 0.82^{\star *}$ & $36.5 \pm 1.1^{*}$ & $129.3 \pm 1.0^{* *}$ \\
\hline
\end{tabular}

$\mathrm{n}=7$; Values are Mean \pm S.E.M; ${ }^{*} \mathrm{p}<0.05$ noteworthy in comparison to control; ${ }^{* *} \mathrm{p}<0.005$ extremely noteworthy in comparison to control.

Table 2. Effect of $N$. nucifera fruit on lipid profile after 45 days.

\begin{tabular}{|c|c|c|c|c|}
\hline \multirow{2}{*}{ Groups } & \multicolumn{4}{|c|}{ Parameters } \\
\hline & Cholesterol mg/dl & Triglycerides mg/dl & $\mathrm{HDL}-\mathrm{C} \mathrm{mg} / \mathrm{dl}$ & LDL-C mg/dl \\
\hline $\begin{array}{c}\text { Control } \\
10 \mathrm{ml} / \mathrm{kg}\end{array}$ & $90.4 \pm 1.0$ & $187.8 \pm 0.80$ & $32.0 \pm 0.72$ & $144.4 \pm 1.2$ \\
\hline $\begin{array}{l}\text { N. nucifera } \\
50 \mathrm{mg} / \mathrm{kg}\end{array}$ & $83.8 \pm 0.74^{\star *}$ & $172.0 \pm 0.82^{\star *}$ & $35.7 \pm 1.2^{\star}$ & $133.1 \pm 0.91^{\star *}$ \\
\hline $\begin{array}{l}\text { N. nucifera } \\
100 \mathrm{mg} / \mathrm{kg}\end{array}$ & $71.3 \pm 0.89^{\star *}$ & $151.4 \pm 0.90^{\star *}$ & $39.8 \pm 0.40^{* *}$ & $112.4 \pm 1.10^{\star *}$ \\
\hline $\begin{array}{l}\text { N. nucifera } \\
200 \mathrm{mg} / \mathrm{kg}\end{array}$ & $54.3 \pm 0.97^{\star *}$ & $131.0 \pm 1.60^{\star *}$ & $43.0 \pm 0.53^{\star \star}$ & $92.4 \pm 0.87^{\star \star}$ \\
\hline
\end{tabular}

$\mathrm{n}=7$; Values are Mean \pm S.E.M; ${ }^{\star} \mathrm{p}<0.05$ noteworthy in comparison to control; ${ }^{\star *} \mathrm{p}<0.005$ extremely noteworthy in comparison to control. 
No deaths of animal were recorded in any group all through the entire period of study. N. nucifera fruit ethanol extract at a dose of $50 \mathrm{mg} / \mathrm{kg}$ exhibited considerable lowering effects on TC after 30 days and extremely noteworthy effects after 45 days in comparison to control. The effects of the same dose of extract highly significantly lowered TG and LDL-C after 30 and 45 days whereas HDL-C was raised significantly after 45 days. $N$. nucifera fruit at a dose of $100 \mathrm{mg} / \mathrm{kg}$ revealed highly significant lowering effects on TC after 30 and 45 days as compared to control, whereas the TG and LDL-C lowering effects were also highly significant after 30 and 45 days in comparison to control. The HDL-C was highly significantly increased after 45 days but was not significantly altered after 30 days in comparison to control. N. nucifera fruit ethanol extract $200 \mathrm{mg} / \mathrm{kg}$ revealed highly noteworthy TC lowering effects after 30 and 45 days in comparison to control, whereas the TG and LDL-C lowering effects were also highly significant after 30 and 45 days in comparison to control. The HDL-C was significantly increased after 30 days and extremely considerably raised after 45 days as compared to control.

\section{Discussion}

Hypercholesterolemia or high levels of cholesterol in the blood are primarily a metabolic derangement that can cause many diseases such as CVD and stroke. Hypercholesterolemia or hyperlipidemia may occur due to abnormalities in lipoproteins, the particles that bring cholesterol to the blood stream. Hyperlipidemia has a strong association with atherosclerosis [22]. LDL cholesterol gets deposited in the blood vessel walls and plays major role in the formation of atherosclerotic plaque. These pathological processes can be reversed by lowering the serum LDL level [23]. Moreover increase in serum HDL level has shown to reduce the progression of atherosclerosis [24] [25].

Current study was distinctively planned to assess the hypolipidemic activities of $N$. nucifera fruit after 30 and 45 days in rabbits kept on high cholesterol diet for 30 days. The results showed remarkable cholesterol lowering effects of $N$. nucifera fruit extract at doses 50, 100 and $200 \mathrm{mg} / \mathrm{kg}$ but were particularly dominant at $200 \mathrm{mg} / \mathrm{kg}$ at which fruit extract highly significantly reduced TC, TG and LDL-C after 30 and 45 days and increased HDL-C significantly after 30 days and highly significantly after 45 days.

Previous studies have established an inverse relationship between flavonoids intake and total lipid concentration in plasma. Diet rich in flavonoids protects against coronary artery diseases [26] [27]. Similarly tannins and procyanidin have demonstrated lipid auto-oxidation and free radical scavenging activity in recent studies [28]. In several studies saponins have been shown to inhibit the intestinal absorption of cholesterol and there by reduces plasma lipid levels in variety of animal models [29] [30].

Previous studies on anti-obesity and hypolipidemic activities of $N$. nucifera seed resulted in inhibition of lipid accumulation and reduced expression of peroxisome proliferator activated receptor gamma (PPAR), leptin in cultured hu- 
man adipocytes and glucose transporter (GLUT 4) indicating the inhibitory effect on the differentiation of pre-adipocytes in to adipocytes [31]. Moreover flavonoids, saponins, tannins and procyanidin are significant constituents of $N$. nucifera fruit, hence it can be postulated that lipid lowering effects of $N$. nucifera fruit can be due to the presence of all of these constituents which can contribute in lowering the risk of CVDs and stroke.

\section{Conclusion}

N. nucifera fruit has exhibited remarkable anti-hyperlipidemic activity which may be due to the presence of secondary metabolites especially flavonoids, saponins, tannins and procyanidin in both segments i.e. seeds and pods of this fruit which may be useful in managing conditions such as CVDs and stroke but more preclinical and clinical studies should be encouraged to confirm these findings.

\section{Acknowledgements}

The authors are thankful to Dr. Mohtesheem, Associate Professor and Chairman Department of Pharmacognosy for identification and authentication of N. nucifera fruits. The authors are also thankful to Prof. Dr. Iqbal Chaudary, Director, HEJ, Research Institute of Chemistry for granting permission to use Institute laboratory and workshop facilities.

\section{Conflict of Interest}

The authors declare no conflict of interest.

\section{References}

[1] Rajput, M.A. and Khan, R.A. (2017) Phytochemical Screening, Acute Toxicity, Anxiolytic and Antidepressant Activities of Nelumbo Nucifera Fruit. Metabolic Brain Disease, 32,743-749. https://doi.org/10.1007/s11011-017-9963-X

[2] Farnsworth, N.R., Kerele, O.A., Bingel, A.S., Soejarto, D.D. and Guo, Z.G. (1983) Medicinal Plants in Therapy, Bull. World Health Organization, 63, 965-981.

[3] Rajput, M.A., Khan, R.A., Qazi, N. and Feroz, Z. (2012) Effect of Methanol Extract of Ajwain (Trachyspermum ammi L.) on Blood Coagulation in Rats. Journal of Liaquat University of Medical and Health Sciences, 11, 105-108.

[4] Mukherjee, P.K., Mukherjee, D., Maji, A.K., Rai, S., Mukherjee, P.K., Saha, K., Pal, M., Saha, B.P. and Heinrich, M. (2009) The Sacred Lotus (Nelumbo Nucifera) Phytochemical and Therapeutic Profile. Journal of Pharmacy and Pharmacology, 61, 407-422. https://doi.org/10.1211/jpp.61.04.0001

[5] Sridhar, K.R. and Bhat, R. (2007) Lotus: a Potential Nutraceutical Source. Journal of Agricultural Science and Technology, 3, 143-155.

[6] Carlo, F.M., Masami, Y., Yoshiaki, K., Ganesh, K.A. and Randeep, R. (2013) Lotus-A Source of Food and Medicine: Current Status and Future Perspectives in Context of the Seed Proteomics. International Journal of Leadership Studies, 7, 1-5.

[7] Indrayan, A.K., et al. (2005) Determination of Nutritive Value and Analysis of Mineral Elements for Some Medicinally Valued Plants from Uttaranchal. Current Science, 89, 1252-1255.

[8] Chopra, R.N., et al. (1956) Glossary of Indian Medicinal Plants. Council of Scientific 
and Industrial Research, New Delhi, 174.

[9] Varshney, C.K. and Rzoska, J. (1976) Aquatic Weeds in South East Asia. 1st edition, Springer, New Delhi, 39.

[10] Ahmed, S., Naved, A., Khan, R.A. and Siddiqui, S. (2015) Analgesic Activities of Methanol Extract of Terminalia Chebula Fruit. Pharmacology \& Pharmacy, 6, 547-553. https://doi.org/10.4236/pp.2015.612056

[11] Irena C., Kazimier, K., Leopold, Andreze, J.K. and Krystyna, S. (1979) Blood Serum protein in Experimental Chronic Liver Injury in Rabbits. The Journal of Pathology, 30, 71-88.

[12] Khan, R.A., Feroz, Z., Jamil, M. and Ahmed, M. (2014) Hypolipidemic and Antithrombotic Evaluation of Myrtus communis L. in Cholesterol-Fed Rabbits. African journal of Pharmacy and Pharmacology, 8, 235-239. https://doi.org/10.5897/AJPP2013.3488

[13] National Advisory Committee for Laboratory Animal Research (2004) Guidelines on the Care and Use of Animals for Scientific Purposes, 24.

[14] National Institute of Health Guidelines for Care and Use of Laboratory Animals in Biomedical Research (2010) Guide for the Care and Use of Laboratory Animals. Prepublication Draft. 8th Edition, The National Academies Press, Washington DC, 6,47 .

[15] Hossain, M.S., Ahmed, M. and Islam, A. (2010) Hypolipidemic and Hepatoprotective Effects of Different Fractions of Ethanolic Extract of Immature Leaves of Mangifera Indica (Linn.) in Alloxan Induced Diabetic Rats. International Journal of Pharmaceutical Sciences Research, 1, 132-138.

[16] Khan, Y., Khan, R.A., Syeda, A. and Afsan, S. (2010) Evaluation of Hypolipidemic Effect of Citrus Lemon. International Journal of Basic and Applied Sciences, 6, 39-43.

[17] Madhu, A., Keerthi, P.H.V., Singh, J. and Shivalinge, G.K.P. (2009) To Evaluate the Anti-Epileptic Activity of Aqueous Root Extract of Hemidesmus Indicus in Rats. Archives of Pharmacal Research, 1, 43-47.

[18] Rajput, M.A., Khan, R.A. and Feroz, Z. (2013) Evaluation of Antiepileptic Activity of Methanol Extract of Trachyspermum ammi. L. Archives of Biological Sciences, 65, 815-819. https://doi.org/10.2298/ABS1303815R

[19] Trinder, P. (1969) Enzymatic Colorimetric Determination of Triglycerides by GPO-PAP Method. Annals of Clinical Biochemistry, 6, 24-27. https://doi.org/10.1177/000456326900600108

[20] Friedwald, W.T., Levy, R.I. and Fredrickson, D.S. (1972) Estimation of the Concentration of Low-Density Lipoprotein Cholesterol in Plasma, without Use of Ultra Centrifuge. Clinical Chemistry, 18, 499-502.

[21] Walpole, R.E. (1982) Introduction of Statistics. 3rd Edition, Macmillan Publishing Company, Inc., New York, 247-304.

[22] Allen, J.K., Young, D.R., Blumenthal, R.S., Moy, T.F., Yanek, L.R., Wilder, L., Becker, L.C. and Becker, D.M. (1996) Prevalence of Hypercholesterolemia among Siblings of Persons with Premature Coronary Heart Disease. Archives of Internal Medicine. Med, 156, 1654-1660.

[23] Ross, R. (1993) The Pathogenesis of Atherosclerosis: a Perspective for the 1900s. Nature, 362, 801-809. https://doi.org/10.1038/362801a0

[24] Stein, O. and Stein, Y. (1999) Atheroprotective Mechanisms of HDL. Atherosclerosis, 144, 285-301. https://doi.org/10.1016/S0021-9150(99)00065-9

[25] Nofer, J.R., Kehrel, B., Fobker, M., Levkau, B., Assmann, G. and Von, E.A. (2002) 
HDL and Arteriosclerosis: Beyond Reverse Cholesterol Transport. Atherosclerosis, 161, 1-16. https://doi.org/10.1016/S0021-9150(01)00651-7

[26] Arai, Y., Watanabe, S., Kimira, M., Shimoi, K., Mochizuki, R. and Kinae, N. (2000) Dietary Intakes of Flavonols, Flavones and Isoflavones by Japanese Women and the Inverse Correlation between Quercetin Intake and Plasma LDL Cholesterol Concentration. Journal of Nutrition, 130, 2243-2250.

[27] Hertog, M.G., Kromhout, D., Aravanis, C., et al. (1995) Flavonoid Intake and LongTerm Risk of Coronary Heart Disease and Cancer in the Seven Countries Study. Archives of Internal Medicine, 155, 381-386. https://doi.org/10.1001/archinte.1995.00430040053006

[28] Ling, Z.Q., et al. (2005) Isolation, Characterization and Determination of Antioxidative Activity of Oligomeric Procyanidins from the Seedpod of Nelumbo Nucifera Gaertn. Journal of Agricultural and Food Chemistry, 53, 2441-2445. https://doi.org/10.1021/jf040325p

[29] Harwood, H.J., Chandler, C.E., Pellarin, L.D., Bangerter, F.W., Wilkins, R.W., Long, C.A., Cosgrove, P.G., Malinow, M.R., Marzetta, C.A., Pettini, J.L., Savoy, Y.E. and Mayne, J.T. (1993) Pharmacologic Consequences of Cholesterol Absorption Inhibition: Alteration in Cholesterol Metabolism and Reduction in Plasma Cholesterol Concentration Induced by the Synthetic Saponin $\beta$-Tigogenin Cellobioside (CP88818; Tiqueside). Journal of Lipid Research, 34,377-395.

[30] Sauvaire, Y., Ribes, G., Baccou, J.C. and Loubatières-Mariani, M.M. (1991) Implication of Steroid Saponins and Sapogenins in the Hypocholesterolemic Effect of Fenugreek. Lipids, 26,191-197. https://doi.org/10.1007/BF02543970

[31] You, J.S, Lee, Y.J., Kim, K.S., Kim, S.H. and Chang, K.J. (2013) Anti-Obesity and Hypolipidaemic Effects of Nelumbo Nucifera Seed Ethanol Extract in Human Pre-Adipocytes and Rats Fed A High-Fat Diet. Journal of the Science of Food and Agriculture, 94, 568-575. https://doi.org/10.1002/jsfa.6297

\section{Submit or recommend next manuscript to SCIRP and we will provide best} service for you:

Accepting pre-submission inquiries through Email, Facebook, LinkedIn, Twitter, etc. A wide selection of journals (inclusive of 9 subjects, more than 200 journals)

Providing 24-hour high-quality service

User-friendly online submission system

Fair and swift peer-review system

Efficient typesetting and proofreading procedure

Display of the result of downloads and visits, as well as the number of cited articles

Maximum dissemination of your research work

Submit your manuscript at: http://papersubmission.scirp.org/

Or contact pp@scirp.org 